\title{
KINETIKA REAKSI TRANSESTERIFIKASI MINYAK GORENG BEKAS DENGAN KATALIS HETEROGEN CaO DARI CANGKANG KERANG DARAH (Andara granosa)
}

\author{
Midiyarti, Nurhayati, Muhdarina \\ Laboratorium Riset Sains Material, Jurusan Kimia, FMIPA, Universitas \\ Riau Jln. Raya Bangkinang KM 12,5 Pekanbaru 28193 \\ E-mail: atik.midiyarti@yahoo.com
}

\section{ABSTRAK}

Biodiesel (Fatty Acid Methyl Ester / FAMEs) is an alternative fuel replacing crud oil (petroleum) which is more friendly to environmen, unsmelling and containing no sulfur. Biodiesel is produced by reacting vegetable oil with alcohol using a base as a catalyst. The transesterification has carried out used waste frying oil with $\mathrm{CaO}$ catalyst from blood mussel shells (Anadara granosa) that calcined at a temperature of $800^{\circ} \mathrm{C}$ for 10 hours as heterogeneous base catalyst. The reaction of transesterification produce products that is optimalized by varying the temperature of the reaction time, and determined by the reaction order. The reaction follows first kinetics order with an activation energy (Ea) which is $93.5 \mathrm{~kJ} / \mathrm{mol}$ and the frequency factor (A) which is $8,16 \mathrm{x}$ 1010min-1. The biodiesel Characterization fuel is measured according to ASTM D 6751. The blood mussel shell (Anadara granosa) is a new source for production of heterogeneous base catalysts that can be used for synthesis biodiesel with high purity.

Keywords: biodiesel, blood mussel shells, kinetics, transesterification

\section{PENDAHULUAN}

Pemakaian Bahan bakar fosil yang tak terbaharukan secara terus menurus dan cenderung meningkat akibat pertumbuhan penduduk dan industri, sementara cadangan minyak semakin berkurang menurut Kurtubi (Tempo, 2013). Mengingat hal diatas maka pencarian sumber energi alternatif yang dapat diperbaharui (renewable), murah dan ramah lingkungan menjadi tuntutan yang tidak dapat ditunda lebih lama lagi. Salah satu energi alternatif yang mempunyai potensi sangat besar namun belum dimanfaatkan secara maksimal adalah bioenergi dimana sumber bahan yang digunakan untuk dikonversi menjadi bahan bakar berasal dari alam sehingga dapat diperbaharui dan tidak menghasilkan emisi gas buang apapun. Beberapa bioenergy yang telah dikembangkan saat ini yaitu biodisel.

Biodisel (Fatty Acid Methyl Ester/FAMEs) merupakan bahan bakar altenatif pengganti minyak bumi yang ramah lingkungan dan sifat kimia biodisel lebih baik daripada diesel dari bahan bakar fosil sehingga penggunaanya lebih efisien (Zu dkk., 2010). Biodisel diproduksi dari reaksi transesterifikasi rantai panjang asam lemak yang berasal dari minyak nabati dan lemak hewani (trigliserida) dengan alkohol alifatik (metanol atau etanol) dengan katalis yang tepat untuk membentuk ester asam lemak rantai panjang (biodiesel) dan gliserol (gliserin) (Srivastava dan Prasad, 2000). Reaksi transesterifikasi dapat dikatalisis oleh asam, basa, atau enzim.

Penggunaan katalis asam dan katalis basa heterogen memiliki keuntungan, yaitu pemisahan dan regenerasi katalis mudah dan murah (Sharma etal., 2008). Katalis heterogen seperti oksida logam alkali tanah seperti $\mathrm{CaO}$, $\mathrm{MgO}, \mathrm{SrO}$, dapat digunakan (Birla., 2012).

Birla. et.al (2012) telah menggunakan katalis hasil dekomposisi cangkang bekicot dalam produksi biodisel dari minyak bekas. Dari penelitian tersebut dapat dikatakan bahwa cangkang bekicot mempunyai potensi untuk digunakan sebagai katalis dalam reaksi transesterifikasi minyak.

Asnibar (2014) telah memanfaatkan cangkang kerang darah (Anadara granosa) sebagai sumber katalis $\mathrm{CaO}$ melalui kalsinasi pada suhu $800^{\circ} \mathrm{C}$ dengan bahan baku minyak goreng bekas dan di peroleh hasil biodisel sebesar $70,20 \%$ pada suhu $60^{\circ} \mathrm{C}$ dengan 
perbandingan molaritas minyak dan metanolnya 1:6.

Penelitian ini dilakukan untuk mempelajari studi kinetika transesterifikasi minyak goreng bekas dengan katalis $\mathrm{CaO}$ dari cangkang kerang darah. Pemahaman lebih lanjut mengenai kinetik reaksi transesterifikasi sangat di perlukan untuk kepentingan desain dan scale-up di industri, dengan menghitung konstanta laju reaksi (k) dan energi aktivasi (Ea) pada berbagai suhu ditentukan.

Hukum laju reaksi transesterifikasi untuk reaksi maju dapat dinyatakan oleh persamaan

$-\mathrm{ra}=\frac{-\mathrm{d}[\mathrm{TG}]}{\mathrm{dt}}=\mathrm{k} .[\mathrm{TG}]$

Dimana [TG] adalah konsentrasi trigliserida $[\mathrm{ROH}]$ adalah metanol dan $\mathrm{k}$ adalah konstanta kesetimbangan (Birla., 2012)

Reaksi keseluruhan ini mengikuti hukum laju reaksi orde dua. Tetapi karena rasio molar metanol yang tinggi terhadap minyak, perubahan konsentrasi metanol dapat dianggap sebagai konstan selama reaksi. Dengan cara mengambil metanol secara berlebihan, konsentrasinya tidak mengubah urutan reaksi dan berperilaku sebagai reaksi orde pertama. Oleh karena itu, reaksi mematuhi pseudo-orde pertama (Zhang et al, 2010). Akhirnya, ekspresi dapat ditulis sebagai berikut:

$-\mathrm{ra}=\frac{-\mathrm{d}[\mathrm{TG}]}{\mathrm{dt}}=\mathrm{K}^{\prime}[\mathrm{TG}]$

di mana $\mathrm{k}$ adalah konstanta laju dimodifikasi dan $\mathrm{k}=\mathrm{k}^{\prime}[\mathrm{ROH}]^{3}$. Dengan berasumsi bahwa konsentrasi trigliserida awal adalah $\left[\mathrm{TG}_{0}\right]$ pada saat $\mathrm{t}=0$, dan pada waktu $\mathrm{t}\left[\mathrm{TG}_{\mathrm{t}}\right]$. Integrasikan ke persamaan 2 untuk $\mathrm{t}=0,[\mathrm{TG}]=\left[\mathrm{TG}_{0}\right]$ dan pada $\mathrm{t}=\mathrm{t},[\mathrm{TG}]=\left[\mathrm{TG}_{\mathrm{t}}\right]$ memberikan persamaan berikut:

$\ln [\mathrm{TGo}]-\ln [\mathrm{TGt}]=\mathrm{k} . \mathrm{t}$

$\mathrm{X}_{\mathrm{me}}=1-\frac{[\mathrm{TG}]}{[\mathrm{TGo}]}$

$[\mathrm{TG}]=[\mathrm{TGo}]\left(1-\mathrm{X}_{\mathrm{me}}\right)$

Dimana $X_{m e}$ adalah konversi metil ester. Persamaan (5) dikonversikan menjadi persamaan berikut:

$\frac{\mathrm{dx} \mathrm{me}_{\mathrm{me}}}{\mathrm{dt}}=\mathrm{k} \cdot\left(1-\mathrm{X}_{\mathrm{me}}\right)$
Yang pada integrasi dan penataan ulang memberi,

$-\ln \left(1-X_{m e}\right)=k . t$

Energi aktivasi adalah energi minimum yang dibutuhkan oleh suatu reaksi kimia agar dapat berlangsung. Pada tahun 1889, Arrhenius mengusulkan sebuah persamaan empirik yang menggambarkan pengaruh suhu terhadap konstanta laju reaksi. Persamaan yang diusulkan adalah:

$\mathrm{k}=\mathrm{A} \mathrm{e} \mathrm{e}^{-\mathrm{Ea} / \mathrm{RT}}$

Keterangan:

$\mathrm{K}=$ konstanta laju reaksi

A $\quad$ faktor frekuensi

$\mathrm{Ea}=$ energi aktifasi

Persamaan dalam logaritma dapat dapat di tulis:

$\ln \mathrm{k}=\ln \mathrm{A}-\frac{\mathrm{Ea}}{\mathrm{RT}}$

$\ln \mathrm{k}=-\frac{\mathrm{Ea}}{\mathrm{R}}\left[\frac{1}{\mathrm{~T}}\right]+\ln \mathrm{A}$

Keterangan:

$\mathrm{K}=$ konstanta laju reaksi

A $\quad=$ faktor frekuensi

$\mathrm{R} \quad=$ konstanta gas $(1,987 \mathrm{kal} / \mathrm{mol} \mathrm{K}$ atau 8,314 J mol-1 K-1)

$\mathrm{Ea} \quad=$ energi aktifasi

$\mathrm{T} \quad=$ suhu mutlak $(\mathrm{K})$

Persamaan tersebut analog dengan persamaan garis lurus, yang sering disimbolkan dengan $y=a x+b$, maka hubungan antara energi aktivasi suhu dan laju reaksi dapat dianalisis dalam bentuk grafik $\ln \mathrm{k}$ vs $1 / \mathrm{T}$ dengan gradien $-(\mathrm{Ea} / \mathrm{RT})$ dan intersep $\ln \mathrm{A}$.

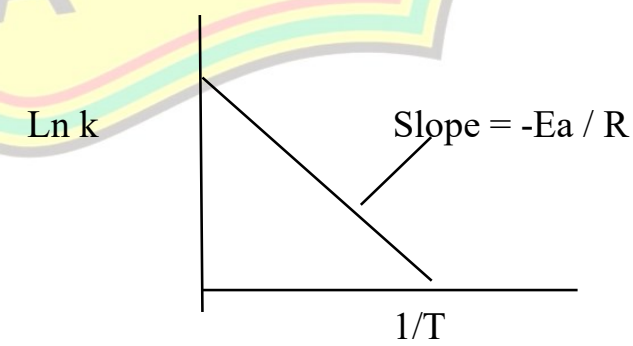

Gambar 1. Grafik In k vs 1/T 


\section{METODOLOGI PENELITIAN}

\section{a. Pengolahan Katalis cangkang kerang}

Cangkang kerang dibersihkan menggunakan air untuk menghilangkan kotoran yang melekat pada cangkang kerang. Cangkang kerang dicuci menggunakan akuades hingga bersih dan ditumbuk kasar dengan mortar martir, setelah itu cangkang kerang dikeringkan dalam oven pada suhu $110^{\circ} \mathrm{C}$ selama 24 jam. Kemudian cangkang kerang di kalsinasi pada suhu 800 selama 10 jam, setelah proses kalsinasi selesai cangkang kerang tersebut digerus serta diayak dengan ayakan 200 mesh dan di simpan dalam desikator

\section{b. Reaksi Transesterifikasi}

Reaksi Transesterifikasi dilakukan dalam labu leher tiga $500 \mathrm{ml}$ yang dilengkapi dengan kondensor, termometer, dan pengaduk magnetik. Limbah minyak goreng (100 gram) ditempatkan kedalam labu reaksi dengan katalis sebanyak 3 gram dan 21,72 gram metanol, lalu dipanaskan dan atur temperaturnya setelah bereaksi sampai waktu tertentu. Pemanasan dilakukan pada suhu konstan.

\section{c. Penentuan Kinetika Reaksi Transesterifikasi}

Untuk menentukan kinetika reaksi, diukur efek suhu reaksi dan waktu reaksi. Setelah reaksi berlangsung setiap 15 menit diambil $2 \mathrm{ml}$ dan dicampurkan dengan campuran $\mathrm{n}$ hexan dan aquades 1:1 sebanyak 4 $\mathrm{ml}$, di kocok dan dibiarkan terjadi pemisahan lalu dianalisa dengan menggunakan GC dengan detektor FID Pengulangan perlakuan dilakukan untuk suhu reaksi 50,55 , dan $60^{\circ} \mathrm{C}$.

\section{d. Analisa Biodisel dengan GC}

Biodisel hasil reaksi transesterifikasi di analisis dengan menggunakan Gas Kromatografi GC 2010 shimadzu dan di karakterisasi berdasarkan SNI 04-7182-2006

\section{HASIL DAN PEMBAHASAN}

Sebelum digunakan sebagai bahan baku pembuatan biodisel, minyak goreng bekas dilakukan pengujian asam terlebih dahulu diukur kandungan asam lemak bebas dan kadar airnya. Hasil pengujian asam lemak bebas minyak goreng bekas pada penelitian ini adalah $0,61 \%$ sehingga untuk sintesis biodiselnya dapat langsung dengan reaksi transesterifikasi tanpa harus melalui reaksi esterifikasi terlebih dahulu.

Pengujian kadar air dari bahan baku minyak goreng bekas yang digunakan pada penelitian ini diperoleh hasil sebesar 0,068\%. Berdasarkan hasil penelitian Freedman,dkk (1989) diketahui bahwa kadar air dari bahan baku untuk proses transesterifikasi yang baik adalah adalah $\leq 0,1 \%$, kadar air yang lebih tinggi akan mengakibatkan inaktivasi katalis logam basa selama reaksi berlangsung, hal ini harus dihindari karena mengakibatkan reaksi akan berjalan sangat lambat atau terhenti. Selain itu dengan kadar air yang relatif tinggi kemungkinan terjadinya hidrolisis semakin besar yang berakibat konversi reaksi transesterifikasi semakin kecil dan pembentukan emulsi semakin besar.

\section{a. Kinetika Reaksi}

Laju reaksi Transesterifikasi minyak goreng bekas menjadi biodisel dapat di tentukan melalui orde reaksinya, orde reaksi ditentukan dengan menggunakan metode grafik yang dicobakan pada 3 tingkatan orde reaksi yaitu orde reaksi 0 , orde reaksi 1 atau orde reaksi 2 Nilai $\mathrm{R}^{2}$ yang tinggi merupakan orde yang sesuai dengan dengan data kosentrasinya. Dari Tabel 1 dapat disimpulkan bahwa laju reaksi tranesterifikasi minyak goreng bekas dengan menggunakan katalis $\mathrm{CaO}$ dari cangkang kerang darah mengikuti orde reaksi 1 sesuai dengan penelitian yang dilkaukan oleh Zhang et al, 2010 yaitu perubahan secara logaritma antara kosentrasi biodisel hasil reaksi transesterifikasi memberikan pengaruh besar.

Untuk menguji orde reaksi 0 dilakukan dengan memplotkan kosentrasi terhadap waktu reaksi dan di peroleh persamaan regresi koefisien determinan $\left(\mathrm{R}^{2}\right)$, dan untuk orde reaksi 1 dilakukan dengan meplotkan $\ln \mathrm{C}$ terhadap $\mathrm{t}$ dan diperoleh persamaan regresi koefisien determinan $\left(\mathrm{R}^{2}\right)$,begitu juga dengan 
orde 2 dengan meplotkan $1 / \mathrm{C}$ terhadap t maka diperoleh koefisien determinan $\left(\mathrm{R}^{2}\right)$. Nilai Koefisien determinan dari masing masing orde reaksi sebagai berikut:

Tabel 1. Perbandingan Orde reaksi dengan nilai $\mathrm{R}^{2}$

\begin{tabular}{|c|c|}
\hline orde & $\mathrm{R}^{2}$ \\
\hline 0 & 0,8422 \\
\hline 1 & 0,9504 \\
\hline 2 & 0,7026 \\
\hline
\end{tabular}

Energi aktivasi reaksi transesterifikasi dihitung menggunakan persamaan Arrhenius. Slope dan intersep dari grafik antara lnk dan 1/T memberikan nilai-nilai energi aktivasi dan faktor frekwensi. Energi aktivasi $\left(E_{a}\right)$ ditentukan dari grafik adalah $93,515 \mathrm{~kJ} / \mathrm{mol}$ dan faktor frekuensi (A) adalah $8,16 \times 10^{10} \mathrm{~min}^{-1}$. Aktivasi energi untuk transesterifikasi minyak goreng bekas lebih besar dari energi aktivasi yang di laporkan oleh Birla (2012) yaitu energi aktivasi yang diperoleh untuk transesterifikasi minyak adalah $79 \mathrm{~kJ} / \mathrm{mol}$ dan faktor frekwensi (A) adalah $2,98 \times 10^{10} \mathrm{~min}^{-1}$ dan juga lebih besar dari kisaran energi aktivasi yang dilaporkan oleh Freedman et al (1986) yaitu energi aktivasi yang diperoleh untuk transesterifikasi minyak kedelai berkisar antara yaitu 33,6 - $84 \mathrm{~kJ} / \mathrm{mol}$

Tabel 2.

Hasil perhitungan parameter persamaan

\begin{tabular}{cccc}
\multicolumn{4}{c}{ Arrhenius } \\
\hline $\mathrm{T}$ & $1 / \mathrm{T}$ & $\mathrm{k}$ & $\ln \mathrm{k}$ \\
\hline 323 & 0,003095975 & 0,0007 & $-7,264430223$ \\
328 & 0,00304878 & 0,0008 & $-7,13089883$ \\
333 & 0,003003003 & 0,002 & $-6,214608098$ \\
\hline
\end{tabular}

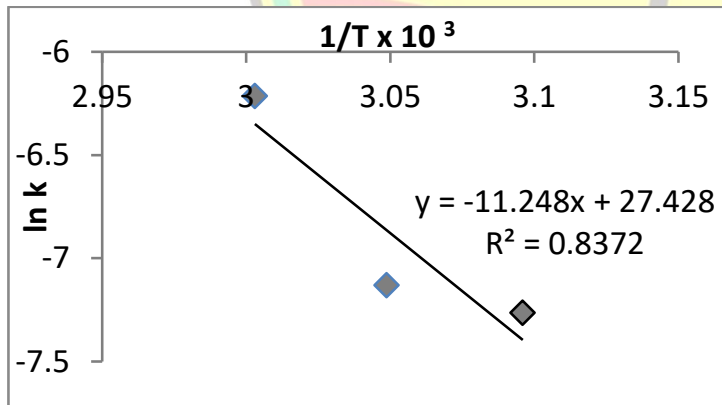

Gambar 2. plot $\ln \mathrm{k}$ versus $1 / \mathrm{T}$ reaksi transesterifikasi minyak goreng bekas dengan katalis $\mathrm{CaO}$

\section{b. Analisis Metil Ester dari Produksi Biodisel Menggunakan GC- MS (Gas Chromatography-Mass Spectroscopy)}

Identifikasi dengan GC-MS dilakukan untuk menyakinkan bahwa hasil sintesis yang diperoleh memang benar merupakan metil ester (biodisel). Hasil analisa GC-MS biodisel terlihat pada gambar 3 dan tabel 3. Dari kromatrogram di peroleh 11 puncak dengan waktu retensi antara 31,94 - 41,09, dari tabel 4.13 terlihat bahwa biodisel yang dihasilkan mengandung 11 senyawa, dengan kelimpahan yang paling tinggi adalah adalah metil oleat yaitu puncak no.7 dengan waktu retensi 39,887 dan \% area 39,43\% setelah itu baru metil palmitat dengan yaitu puncak no. 4 dengan waktu retensi 36,405 dan \% area $28,82 \%$ dan puncak yang paling kecil adalah puncak no. 2 dengan waktu retensi 35,742 dengan $\%$ areanya $0,06 \%$, dari kromatogram juga tidak terlihat puncak karakteristik monogliserida, digliserida dan trigliserida menunjukkan bahwa reaksi transesterifikasi minyak goreng bekas dengan katalis $\mathrm{CaO}$ dari cangkang kerang darah telah selesai dengan menghasilkan menghasilkan biodisel dengan kemurnian yang tinggi $(>90 \%)$.

Dari data GC-MS dapat disimpulkan bahwa hasil sintesis dari penelitian ini adalah memang merupakan senyawa metil ester (biodisel). Senyawa penyususun dalam metil ester yang dominan adalah metil oleat $(39,43 \%)$, metil palmitat $(28,82 \%)$ dan metil linoleat $(8,42 \%)$. Ester-ester tersebut merupakan pecahan dari asam lemak penyusun trigliserida dalam minyak goreng bekas. 


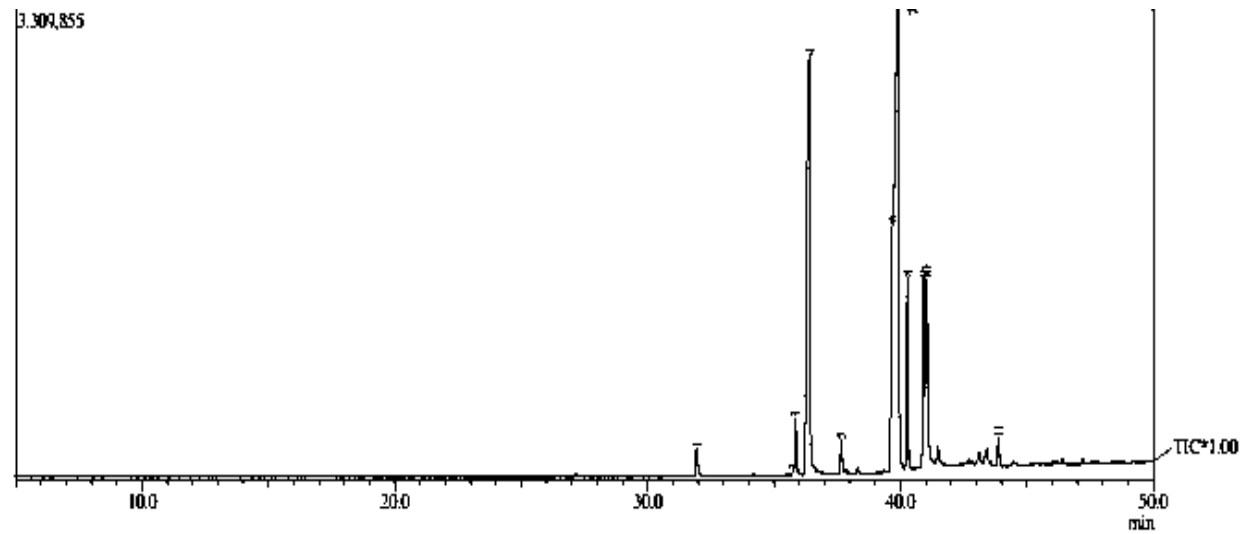

Gambar 3. Kromatogram GC dari Produk Biodisel

Tabel 3. Hasil Analisa GC-MS dari biodisel

\begin{tabular}{|c|c|c|c|c|}
\hline $\begin{array}{c}\text { No } \\
\text { puncak }\end{array}$ & $\begin{array}{c}\text { Waktu } \\
\text { Retensi } \\
(\text { min) }\end{array}$ & Metyl ester & Berat Molekul & $\begin{array}{c}\text { \% } \\
\text { area }\end{array}$ \\
\hline 1 & 31,942 & $\begin{array}{c}\text { Tetradecanoic acid, methyl ester } \\
\text { (CAS) Methyl myristat }\end{array}$ & $\mathrm{C}_{15} \mathrm{H}_{30} \mathrm{O}_{2}(242)$ & 0,94 \\
\hline 2 & 35,742 & Methyl palmitoleate & $\begin{array}{c}\mathrm{C}_{17} \mathrm{H}_{32} \mathrm{O}_{2}(268) \\
\mathrm{C}_{19} \mathrm{H}_{36} \mathrm{O}_{2}(296)\end{array}$ & 0,06 \\
\hline 3 & 35,852 & Methyl palmitoleate & $\mathrm{C}_{17} \mathrm{H}_{32} \mathrm{O}_{2}(268)$ & 1,95 \\
\hline 4 & 36,405 & methyl ester Methyl palmitate & $\mathrm{C}_{17} \mathrm{H}_{34} \mathrm{O}_{2}(270)$ & 28,82 \\
\hline 5 & 37,661 & ethyl ester Ethylpalmitat & $\mathrm{C}_{18} \mathrm{H}_{36} \mathrm{O}_{2}(284)$ & 0,94 \\
\hline 6 & 39,675 & methyl ester Linoleic acid & $\mathrm{C}_{19} \mathrm{H}_{34} \mathrm{O}_{2}(294)$ & 8,42 \\
\hline 7 & 39,887 & methyl ester Methyl oleate & $\mathrm{C}_{19} \mathrm{H}_{36} \mathrm{O}_{2}(296)$ & 39,43 \\
\hline 8 & 40,28 & methyl ester Methyl stearat & $\mathrm{C}_{19} \mathrm{H}_{38} \mathrm{O}_{2}(298)$ & 5,68 \\
\hline 9 & 40,927 & Linoleic acid ethyl ester & $\mathrm{C}_{20} \mathrm{H}_{36} \mathrm{O}_{2}(306)$ & 6,42 \\
\hline 10 & 41,049 & Linolenic acid (C18:3) & $\mathrm{C}_{21} \mathrm{H}_{34} \mathrm{O}_{2}(306)$ & 6,62 \\
\hline 11 & 41,049 & $\begin{array}{c}\text { Arachidic acid/Eicosanoic acid, } \\
\text { methyl ester }\end{array}$ & $\mathrm{C}_{21} \mathrm{H}_{42} \mathrm{O}_{2}(326)$ & 0,71 \\
\hline & & & & \\
\hline
\end{tabular}

Dari tabel 3 terlihat molekul yang dominan pada minyak goreng bekas tersebut adalah metil oleat $(39,43 \%)$, metil palmitat $(28,82 \%)$ dan metil linoleat (6,62\%). Sehingga dapat disimpulkan bahwa molekul penyusun trigliserida dari minyak goreng bekas tersebut adalah asam oleat, asam palmitat dan asam linoleat, sehingga molekulnya dapat dituliskan sebagai $\mathrm{RCO}_{2} \mathrm{CH}_{2} \mathrm{CH}\left(\mathrm{O}_{2} \mathrm{CR}^{\prime}\right) \mathrm{CH}_{2} \mathrm{OCR}$ " dengan $\mathrm{R}$ berasal dari asam oleat, $\mathrm{R}$ ' dari asam palmitat dan R" dari asam linoleat.

Konversi asam Lemak metil ester (biodisel) detentukan menjadi metil ester (biodisel) ditentukan dengan menggunakan Shimadzu Sistem Kromatografi Gas 2010 dilengkapi dengan leburan silika kolom kapiler (DB-5HT; $0,32 \mathrm{~mm} 30 \mathrm{~m}$ ) dan detektor FID. Pada gambar 4. terlihat bahwa peningkatan secara bertahap konversi biodisel pada waktu 1-5 jam, peningkatan drastis terlihat pada waktu reaksi 2- 4 jam setelah waktu 4 jam kenaikan tidak begitu banyak. Semakin lama waktu yang digunakan untuk reaksi semakin besar pula konversi yang dicapai, hal ini menunjukkan bahwa semakin lama waktu reaksi maka semakin banyak tumbukan yang terjadi dan kecepatan reaksi ke kanan lebih besar bila dibandingkan dengan kecepatan reaksi ke kiri sehingga konversi semakin meningkat.

Tabel 4.

Waktu reaksi dan luas areal pada GC di berbagai suhu

\begin{tabular}{|c|c|c|c|}
\hline waktu & $\mathbf{5 0}^{\mathbf{}} \mathbf{C}$ & $\mathbf{5 5}^{\circ} \mathbf{C}$ & $\mathbf{6 0}^{\circ} \mathbf{C}$ \\
\hline 1 & 4817839 & 2347815 & 604416 \\
\hline 2 & 5717009 & 1725039 & 849244 \\
\hline
\end{tabular}




\begin{tabular}{|c|c|c|c|}
\hline waktu & $\mathbf{5 0}^{\mathbf{}} \mathbf{C}$ & $\mathbf{5 5}^{\mathbf{}} \mathbf{C}$ & $\mathbf{6 0}^{\mathbf{}} \mathbf{C}$ \\
\hline 3 & 5825092 & 5644491 & 8867851 \\
\hline 4 & 12261750 & 15251781 & 16720247 \\
\hline 5 & 13924988 & 15592071 & 18780659 \\
\hline
\end{tabular}

12-Tahun, (Tanggal Akses: 6 April 2015).

Badan Standar Nasional. 2006. Standar Nasional Indonesia 04-7182-2006 Biodiesel.

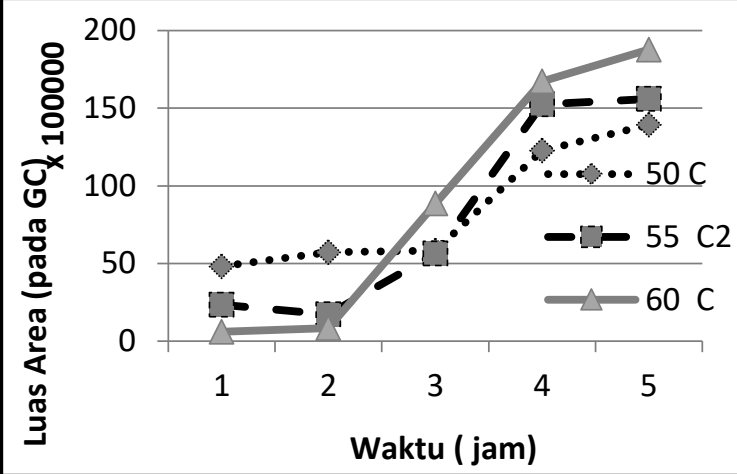

Gambar 4. Grafik pengaruh waktu reaksi terhadap konversi biodiesel

4. KESIMPULAN

1. Dari data analisis GC-MS biodisel diperoleh metil ester yang tertinggi adalah metil oleat $(39,43 \%)$, metil palmitat $(28,82 \%)$ dan metil linoleat $(6,62 \%)$.

2. Laju reaksi tranesterifikasi minyak goreng bekas dengan menggunakan katalis CaOdari cangkang kerang darah yang dikalsinasi pada suhu $800^{\circ} \mathrm{Cselama} 10$ jam mengikuti kinetika reaksi orde 1 dengan energi aktivasi ( $E_{a}$ adalah 93,515 $\mathrm{kJ} / \mathrm{mol}$ dan faktor frekuensi (A) adalah $8,16 \times 10^{10} \mathrm{~min}^{-1}$.

\section{DAFTAR PUSTAKA}

Agrawal. S., Singh. B., Sharma.Y.C., 2012., Exoskeleton of Mollusk (Pilaglobosa) As A Heterogeneous Catalyst For Synthesis of Biodiesel Using Used Frying Oil. Ind. Eng. Chem. Res. 2012, 51, 11875-11880.

Asnibar,S. 2014. “ Transesterifikasi Minyak goreng bekas untuk produksi Biodisel dengan Katalis $\mathrm{CaO}$ dari Limbah Cangkang kerang Darah (Anadara granosa) Kalsinasi $800^{\circ} \mathrm{C}$. Skripsi.Jurusan Kimia FMIPA. Universitas Riau.

Anonim.2013.http://www.tempo.co/read/news/ 2013/12/17/090538193/PengamatCadangan-Minyak-Indonesia-Tinggal-
Birla, A., Singh, B., Upadhyay, S.N., Sharma, Y.C. 2012., " Kinetics Studies of Synthesis of Biodiesel from Waste Frying Oil Using a Heterogeneous Catalyst Derived From Snail Shell”. Bioresource Technology. 106 95-100.

Freedman, B., Butterfield, R.O., Pryde, E.H., 1986. "Transesterification kinetics of soybean oil ". J.AM. Oil Chem. Soc. 63, 1375-1380.

Sharma YC., Singh.B.\& Korsta.J.2011. "Advancecements in solid acid catalysts for ecofriendy en economically viable synthesis of biodiesel, biofuel, bioprod" Bioref 5:69-92

Srivastava.A \& Prasad R., 2000,'Triglyceridesbase dieselfuel"., renewsuat energi Rev 4 (2): 111-133

Yuniwati, M., Abdul, K., H., 2009.“ Kinetika Reaksi Pembuatan Biodiesel dari minyak goreng bekas (jelantah) dan Metanol dengan katalis $\mathrm{KOH}$ " Jurnal Teknologi Vol.2No.2 Desember 2009, hal 130-136.

Zhang.L., Sheng.B.,Xin.Z., Liu.Q dan Sun.S., 2010., " Kinetics of transesterification of Palm oil and dimethyl carbonate for biodiesel production at the catalysis of heterogeneous base catalyst ". Bioresource Technology 101 81448150.

Zu, Y., Liu, G., Wang, Z., Shi, J., Zang, M., Zhang, W., and Jia, M. 2010. CaO Supported on Porous Carbon as Highly Efficient Heterogeneous Catalysts for Transesterification of Triacetin with Methanol. Energy Fuels. 3810-3816. 